\title{
Research on the policy of renewable energy development in China
}

\author{
Chen $\mathrm{Xi}^{1 *}$, Guo Ting ${ }^{2}$, Feng Zhi'an ${ }^{2}$, Qian $\mathrm{Wei}^{2}$ \\ ${ }^{1}$ Guangdong University of Foreign Studies, Guangzhou Guangdong, 511363, China \\ ${ }^{2}$ Nanfang College Guangzhou, Guangzhou, Guangdong, 510970, China
}

\begin{abstract}
On the 19th National Congress of the Communist Party of China, It is stressed that that China will establish and improve the economic system of green and low-carbon circular development and promote the reform of energy system and develop the renewable energy, and then it is urgent for China to not only master the basic laws of the world's renewable energy development, comply with the trend and trend of energy reform, but also promote the development of renewable energy based on national conditions and regional conditions, so as to achieve higher quality development of economy and society.
\end{abstract}

\section{Preface}

Although great progress has been made in the development of renewable energy industry in China, it is far from meeting the requirements of China's energy development strategy. The development of renewable energy is objectively due to the high cost of wind power generation and solar power generation slowly. In addition, the intermittent and unstable power generation and the problem of energy storage have not been well solved. Therefore, it is necessary to promote the development of renewable energy by supporting special energy policies, reflecting the will of the country. Energy security is a global issue, it is impossible for most countries to obtain energy security without international cooperation. Energy is an important material basis for China to build a well-off society in an all-round way, realize modernization and enrich the people. China will work hard to solve the energy problem and unswervingly follow the path of sustainable energy development.

\section{Energy policy in the new era}

With the global climate change becoming more and more prominent the international community's general concern for the problem is rising, countries around the world have adjusted their energy strategies to increase the proportion of clean and renewable energy. In 2016, the world's new investment in renewable energy was about US \$241.6 billion (excluding large-scale hydropower), about 5.14 times of that in 2004. The global total installed capacity of renewable energy power generation can provide about $24.5 \%$ of the world's total power. In China, the development of renewable energy has also made some breakthrough and landmark achievements. In 2016, China's renewable energy power and fuel investment and the total installed capacity of renewable energy power generation ranked first in the world. In 2017, photovoltaic and wind power accounted for $6.6 \%$ of the country's total power generation. At present, countries and international organizations have put forward future development goals for renewable energy. The EU requires its member states to achieve $20 \%$ of energy demand by 2020 from renewable energy; the German government plans to increase the proportion of renewable energy from $33 \%$ to $40 \%$ to $45 \%$ by 2025 , and to $55 \%$ to $60 \%$ by 2035.According to the 13th five-year plan for the development of renewable energy in China, by 2020, China will achieve an annual utilization of 730 million tons of standard coal, of which renewable energy power generation will reach $27 \%$ of the total.

\section{14th five year plan renewable energy development}

Renewable energy is an important part of energy supply system. At present, the scale of global renewable energy development and utilization is expanding, and the application cost is dropping rapidly. The development of renewable energy has become the core content of many countries to promote energy transformation and an important way to cope

\footnotetext{
*Corresponding author's e-mail: 499957639@qq.com
} 
with climate change, as well as an important measure to promote energy production and consumption revolution and energy transformation in China. During the 12th Five Year Plan period, China's renewable energy has developed rapidly and made important contributions to the adjustment of China's energy structure. In the period of "13th FiveYear", the decisive stage of building a well-off society in an all-round way is also a crucial period for deepening the reform in an all-round way. It is also the key period to implement the energy development strategy of "four revolutions and one cooperation" proposed by general secretary Xi Jinping. In order to achieve the goals of $15 \%$ and $20 \%$ of primary energy consumption for non fossil energy in 2020 and 2030, accelerate the establishment of a clean and low-carbon modern energy system, and promote the sustainable and healthy development of renewable energy industry, in accordance with the requirements of the renewable energy law, in accordance with the 13th five year plan outline for national economic and social development of the people's Republic of China and the 13th five year plan outline for energy development "Plan", and formulate the 13th five year plan for renewable energy development. It includes water energy, wind energy, solar energy, biomass energy, geothermal energy and marine energy. It defines the guiding ideology, basic principles, development objectives, main tasks, optimization of resource allocation, innovation of development mode, improvement of industrial system and safeguard measures for the development of renewable energy in China from 2016 to 2020, as an important guide for the development of renewable energy in the 13th Five Year Plan period.

\section{The policy of renewable energy development in China}

The transformation of energy from pollution to clean, from high carbon to low carbon is a longterm, gradual and abrupt process, involving multiple technologies, industries and different subjects, which is a complex system evolution process. There are differences in the development of each country due to its different national conditions. Generally speaking, the development of renewable energy in the world is still in the exploration period of "crossing the river by feeling the stone". The choice of strategy and path has certain randomness, and the supply of policy has certain exploratory nature, which also brings some problems in the development process of renewable energy.

First, uncertainty is increasing due to changes in technology and markets. At present, the development of renewable energy has achieved phased goals. However, while making progress, we often neglect the deep understanding of the general laws and driving mechanism of renewable energy development, which affects the rationality of strategic planning objectives, and causes many problems such as "unclear strategy", "unreasonable planning layout" of renewable energy. The impact of strategic problems on the development of renewable energy is often long-term and systematic. In 2017, the installed capacity of renewable energy power generation in China increased by $14 \%$ year-on-year, but the rate of "wind and light abandonment" reached $12 \%$ and $6 \%$ respectively, which to some extent was related to the lack of recognition of the law.

Secondly, the efficiency of resource allocation in policy investment is becoming increasingly prominent. Economic incentives such as installation subsidies and fixed feed in tariffs are one of the main driving forces for the development of renewable energy. These policies ensure the economic benefits of investment in renewable energy, and can effectively stimulate the demand for renewable energy in the short term. However, due to the lack of or less consideration of the inherent needs and laws of sustainable development of renewable energy, these policies may bring about problems such as "policy failure", "low efficiency" and "unsustainable subsidies". At the same time, if the policy design ignores the role orientation and behavior mechanism of different subjects (government, enterprises, consumers), it will often lead to problems such as "difficulty in coordinating the interests of the subject" and "alienation of the subject's behavior". The feedback of these problems to the policymaking process will cause the instability and unsustainability of the policy, lead to the frequent adjustment of renewable energy 
development planning objectives, and the implementation mode of the policy (such as subsidy level, subsidy form, etc.) often changes.

Third, in the new era, the spatial heterogeneity of renewable energy development has become increasingly prominent, resulting in more and more prominent policy effectiveness issues. Restricted by regional heterogeneity such as resource distribution, market structure and industrial environment, the development of renewable energy shows obvious regional differences, such as wind power development based on resource base in Northeast, North and Northwest China. Therefore, in the process of renewable energy development, various countries and regions have formed diversified development paths in policy, technology, market and other aspects. For example, in terms of the target design of renewable energy development planning, Japan, Spain, etc. set out the target from the proportion of primary energy; the EU, Brazil, etc. set out the target from the proportion of final energy consumption; China is based on energy conservation and emission reduction, from the carbon intensity target, to the proportion of renewable energy.

\section{Development path of renewable energy in China}

In the 14 the Five-Year Plan which is the key period to carbon peaking, China should focus on several tasks, one of which is to build a clear Clean low-carbon safe and efficient energy system, control the total amount of fossil energy, and focus on Improve utilization efficiency, implement renewable energy substitution actions, and deepen electric power System reform, build a new power system with new energy as the main body. In the new era, the development of renewable energy is becoming more and more systematic and complicated. Therefore, it is urgent to make overall consideration and systematic planning from the strategic level, and accelerate the construction of a renewable energy development path that meets the general requirements of "beautiful China".

Firstly, we need to plan as a whole at the strategic level. We must pay more attention to the overall understanding and grasp of the law of renewable energy development, and pay more attention to the in-depth study of market, technology, consumers and other driving factors and driving mechanism. On this basis, the national strategy of renewable energy development should be clarified, the regional layout and system structure of renewable energy development should be reasonably planned, and the long-term and effective development path of renewable energy should be constructed.

Second, we need to design more stable and effective policies. At present, the development of renewable energy shows the characteristics of multi-agent complex dynamic game. The marginal social benefits of renewable energy are gradually reduced, the cost pressure of incentive policy implementation is increasing, the resource allocation efficiency of policy investment is increasingly prominent, and the leverage role of policy is gradually weakened. It is urgent for relevant departments to start from the internal needs of different subjects, and further explore their decision-making motivation, decision-making behavior and its impact. On this basis, we should integrate the interest demands of each subject, improve the interest distribution mechanism, and design more effective and stable policies.

Third, we need to enhance the universality and diversity of policies. Due to the differences in industrial structure and consumption structure, some places also have diversified choices in the development of renewable energy. Now, it is urgent to study the universality and differences of policies and determine long-term strategic guidance policies. On this basis, based on national conditions, provincial conditions and regional conditions, we should formulate more targeted, flexible and effective policies in terms of resource endowment, economic structure and environmental conditions, and build a renewable energy development path in line with the general requirements of "beautiful China".

\section{6 conclusion}

Although great progress has been made in the development of renewable energy industry in China, it is far from meeting the requirements of China's energy development strategy. The development of renewable energy is objectively 
due to the high cost of wind power generation and solar power generation slowly. In addition, the intermittent and unstable power generation and the problem of energy storage have not been well solved. Therefore, it is necessary to promote the development of renewable energy by supporting special energy policies, reflecting the will of the country. Energy security is a global issue, it is impossible for most countries to obtain energy security without international cooperation. Energy is an important material basis for China to build a well-off society in an all-round way, realize modernization and enrich the people. China will work hard to solve the energy problem and unswervingly follow the path of sustainable energy development.

\section{Reference}

1. Zhang,D.,(2019)Research on the development and utilization of renewable energy in China. Jilin electric power,47 (05): pp. 5-8.

2. Ma, L.,Li, XF.,(2019)Experience and Enlightenment of international renewable energy development. China power enterprise management, 31: pp. 92-95.

3. Zhang, SW., (2019) Coal power and renewable energy: complementary or alternative. Energy, 11: pp.24-27.

4. Chen, BY., Xue, LF., (2019) Gu Hongbin. Environmental impact and suggestions on renewable energy development. Hydropower, 45 (10): pp. 1-5.

5. Lou, W.,.(2019)Development of renewable energy technology in China (1949-2019). Science and technology guide, 37 (18): pp. 155-161.

6. Zhou, YH.,(2019) Wen lichen. Research on the current situation of renewable energy development under energy transformation. Marketing, 37: pp. 241242. 